\title{
CONTRIBUTION OF NON-STRUCTURAL CONCRETE WALLS TO THE FIRE RESISTANCE OF UNPROTECTED STEEL FRAMES
}

\author{
Tom Molkens ${ }^{\mathrm{a}}$, François Hanus ${ }^{\mathrm{b}}$ \\ ${ }^{a}$ StuBeCo bvba, Engineering office, Overpelt, Belgium \\ ${ }^{\mathrm{b}}$ ArcelorMittal Global R\&D, Long Products, Esch/Alzette, Luxembourg
}

\begin{abstract}
In the scope of a new industrial building, an R60 fire resistance criterion was requested by the local fire brigade for the steel structure supporting non-structural EI60 concrete walls. On the basis of an investigation conducted after an actual fire in 2008, it was presumed possible to satisfy this R60 criterion using this type of unprotected steel frame. A 2D thermo-plastic model was set up, taking into account the thermal contribution of concrete walls, to limit excessive steel temperatures of the bearing elements. A void was considered between the concrete and the web of the middle columns to simulate real construction works as much as possible. The nominal ISO-834 fire was applied separately in each bay on the exposed parts of the elements. By using fixed column bases in case of fire, the structure can withstand up to 120 minutes of ISO fire i.e. far beyond the collapse of the primary structure subjected to fire. To avoid discussions about the local impact of a real fire, the investigation was extended to columns subjected to a local fire.
\end{abstract}

Keywords: multiple bay frame, non-structural concrete, thermo-plastic design, void, local fire

\section{INTRODUCTION}

In the scope of a new steel industrial building (R15 requirement), the local fire brigade of Lommel (Belgium) also requested an R60 fire resistance for the partition walls. According to the regulations, partition walls should meet EI criteria to avoid the spreading of smoke between sub-compartments.

The steel structure is made up of 4-bay frames. The beam-to-column connections are rigid and the column bases are assumed to be hinged for the cold design. The concrete partition walls are inserted between the flanges of unprotected steel columns, with a $10 \mathrm{~mm}$ void between the panel and web.

The horizontal forces developed in industrial halls with protected columns have been calculated according to the design rules resulting from the European collaborative project "Fire Safety of Industrial Hall" (RFSC Research, 2007). This report describes how this concept could be applied to industrial halls with unprotected columns, only the thermal contribution of concrete walls was used. Numerical simulations were made using SAFIR software (Franssen, 2005) under the assumption of rigid column bases and accounting for the contribution of concrete walls in thermal analyses.

In the past, similar structures have been subjected to severe fire loads and no structural damage was been observed in the unprotected steel columns, although beam failures were observed.

\section{OBSERVATIONS}

In 2008, a consultancy report was requested by the Euroshoe Company after a fire broke out in a shop in Tournai, Belgium (Figure 1). The fire in the adjacent shop affected one bay of the construction, which was made out of 3 equal continuous bays. Partition walls consisted of HEA180 profiles with light cellular concrete infill panels (with a density of $650 \mathrm{~kg} / \mathrm{m}^{3}$ ). The profile factor and infill material were more disadvantageous than in this case study, and the height of the building was limited to about $4.20 \mathrm{~m}$.

The fire wall passed the roof by only $50 \mathrm{~cm}$, but there was only damage to water tightness without structural consequences. BWI (Belgian Welding Institute npo, 2008) investigations confirmed that after the fire, the hardness level and ferrite-pearlite crystal structure remained unchanged after rolling. The fire brigade removed some roof cladding for access reasons (Figure 1). 

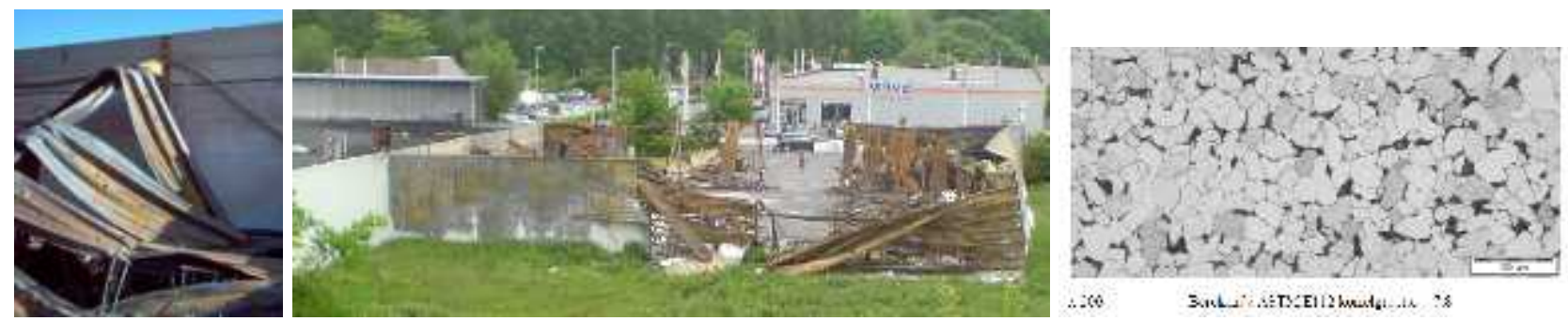

Figure 1. Pictures after fire from the Euroshoe shop at Tournai (Belgium) \& crystal structure

\section{DESIGN ASSUMPTIONS}

\subsection{Geometry}

The industrial building at ambient temperature was designed by Metaalwerken Ivo Gijbels (MIG). The industrial building has the following properties (no office areas), Fig. $2 \& 3$ :

- Total surface area $57 \mathrm{~m}$ by $25.5 \mathrm{~m}=1453.5 \mathrm{~m}^{2}$ or smaller than $2000 \mathrm{~m}^{2}$.

- Hall divided in 4 different areas as follows: $19.2+3 \times 12.6 \mathrm{~m}$, roof slope of the $3 \%$.

- Partition walls made of precast concrete panels up to the roof, placed between the flanges of HEB180 columns which support the principal roof beams (10 $\mathrm{mm}$ void to web).

- Level roof ridge at $8.9 \mathrm{~m}$ above ground level, with no levels in between.

- Connection with spread footing with the aid of 4 anchors/columns; in cold design mentioned as a pinned connection - in fire condition clamped in. All other connections are rigid.

- Bay distance $6.3 \mathrm{~m}$, cladding in precast concrete with insulated sandwich panels.

- Sinusoidal imperfection of L/1000 applied to the beams.

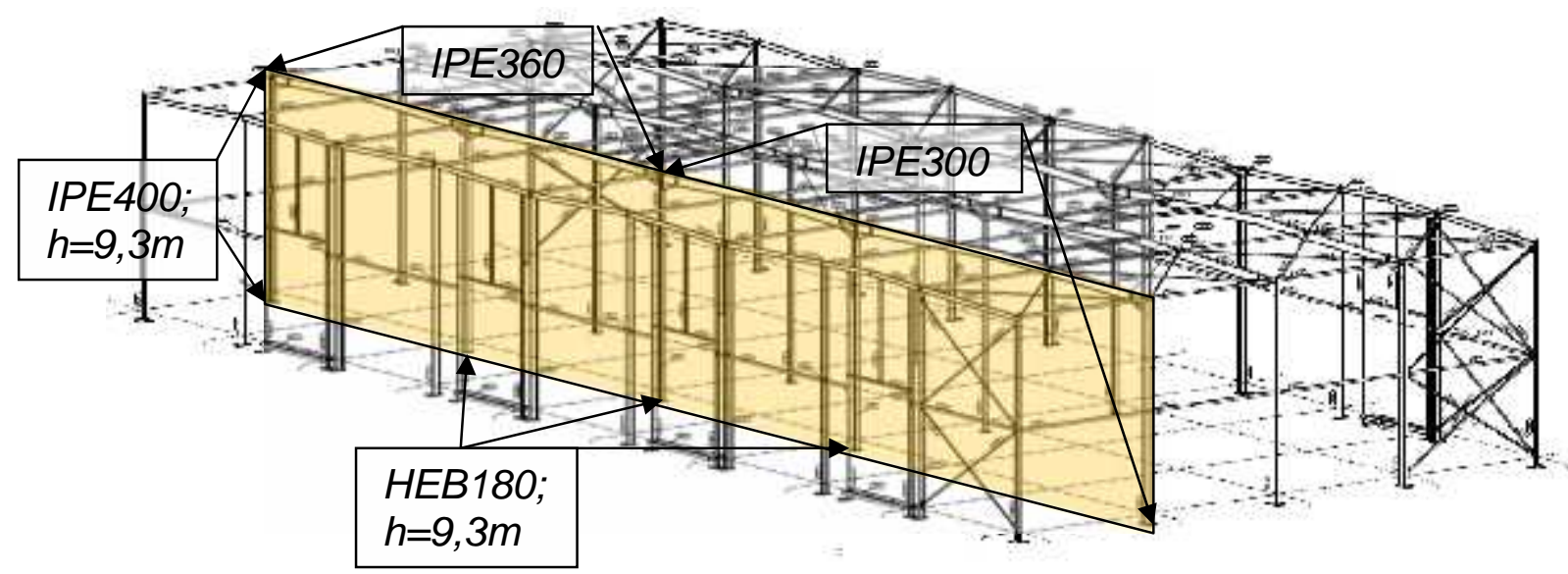

Figure 2. Steel structure with indication of the 4 bay 2D frame, object of the simulation.

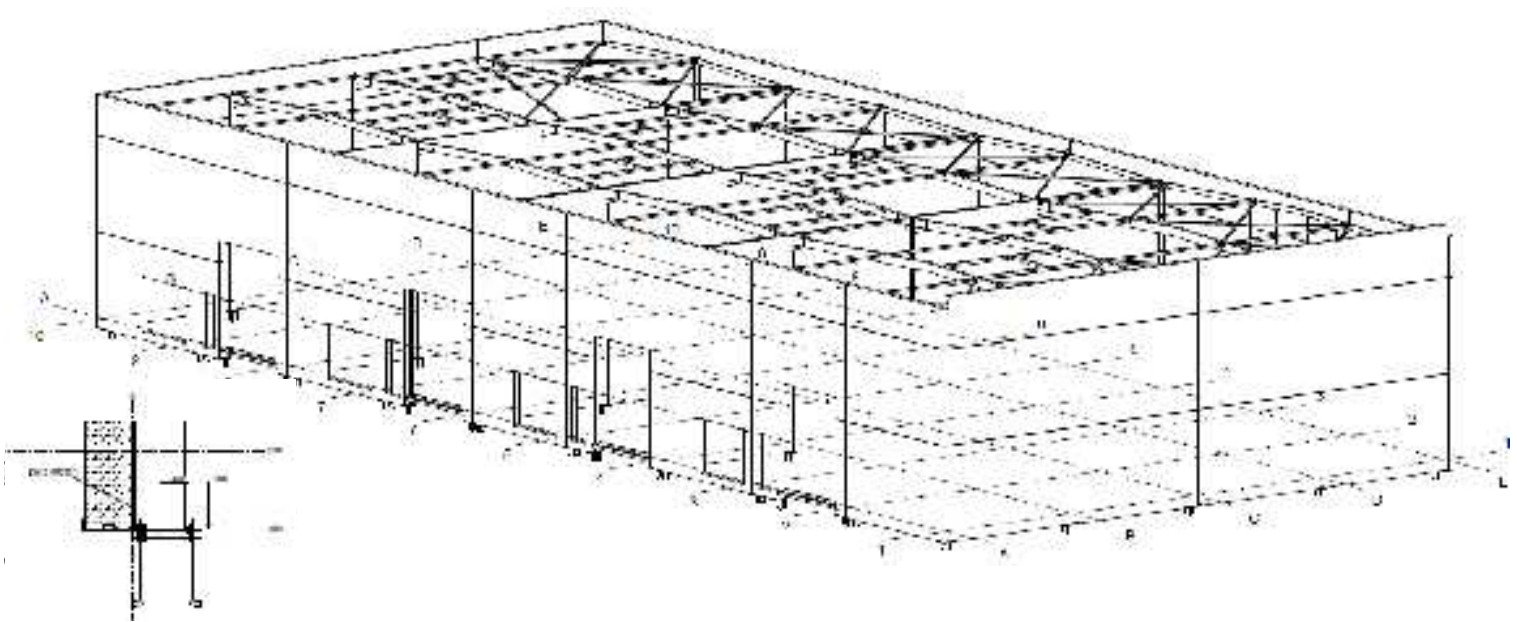

Figure 3. Structure with cladding and detail of the connection with the spread footing. 


\subsection{Loads}

The roof consists of a roof decking, insulation and PVC tightness $=0.10+0.036+0.025 \mathrm{kN} / \mathrm{m}^{2}$. To account for the effect of the continuity from the roof decking, a magnification factor of 1.15 was introduced. Dead load of the profiles themselves was also added.

Wind action was determined according to EN 1991-1-4 with a basic pressure of $0.673 \mathrm{kN} / \mathrm{m}^{2}$. The external and internal pressure coefficients were $c_{p e}=0.70 /-0.30-c_{p i}=-0.30$ for the first and third bay. Considering a distance between the frames of $6.30 \mathrm{~m}$ with a combination factor $\Psi_{1}=0.20$ results in line loads of 849 and $255 \mathrm{~N} / \mathrm{m}$. The influence of wind on the roof is not taken into account (conservative).

Each different sub-compartment was heated following ISO834, with ambient conditions at $20^{\circ} \mathrm{C}$ for the outside or adjacent compartments.

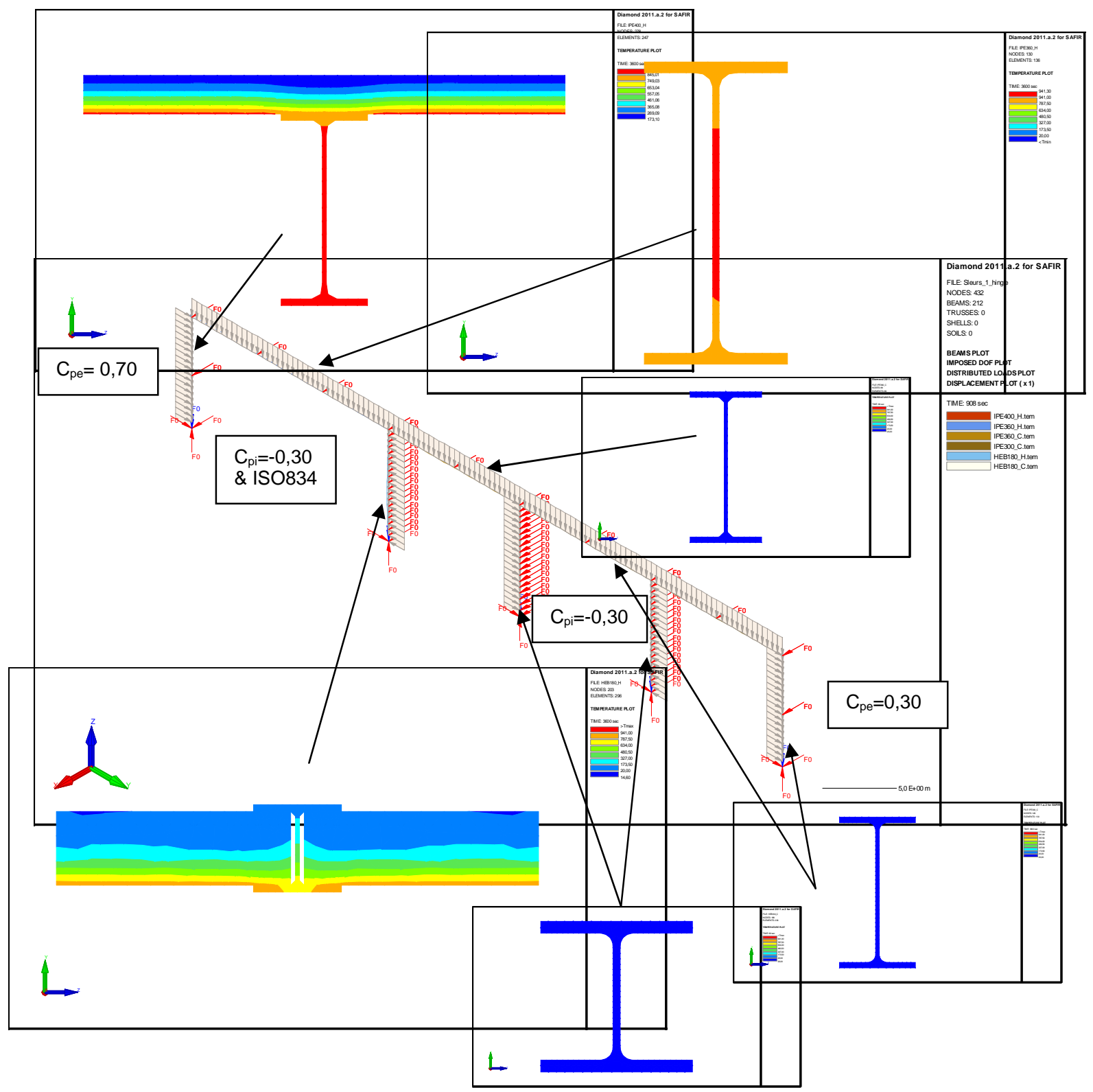

Figure 4. Restraints, loads and results of thermal calculation after $3600 \mathrm{~s}$.

\subsection{Materials}

The material properties for the S235 grade structural steel are derived from EN 1993-1-2. The shadow effect is taken into account by applying reduction factors to basic values, namely $\alpha_{c}=25$ $\mathrm{W} / \mathrm{m}^{2} \mathrm{~K}$ and $\varepsilon=0.70$. Non-structural concrete infills were introduced as an insulation material (to avoid structural response) with thermal data from EN 1994-1-2 normal weight concrete (2400 
$\mathrm{kg} / \mathrm{m}^{3}$ ) suitable for simple calculation models; $\lambda=1.60 \mathrm{~W} / \mathrm{mK}, \mathrm{c}=1000 \mathrm{~J} / \mathrm{kgK}, \alpha_{\mathrm{h}}=25 \mathrm{~W} / \mathrm{m}^{2} \mathrm{~K}, \alpha_{\mathrm{c}}$ $=4 \mathrm{~W} / \mathrm{m}^{2} \mathrm{~K}$ and $\varepsilon=0.70$.

\section{DESIGN STRATEGY}

The fire resistance of the structure was analysed using a two-step approach. In a first run, the failure mode and time of the structure were recorded (the first failure was always observed in the heated sub compartment). Subsequently, a second run started up with the residual structure. Columns on the fire side were continuously heated and an extra horizontal force, calculated using the simplified catenary theory (RFSC Research), was applied to the top of the column.

\subsection{Action of the heated part on the cold part.}

After collapse of the heated part, a horizontal force is applied continuously to the top of the cold sub-structure. The stability of the remaining sub-structure must consequently be checked considering this additional force $F$, determined by the simplified catenary theory given in Eq. (1).

$$
F=c_{p} n_{\text {eff }} q l
$$

where $F \quad$ horizontal force acting on the top of the residual structure,

$c_{p} \quad$ empirical coefficient function of the slope equal to 1.17 for $3 \%$,

$n_{\text {eff }} \quad$ coefficient taking into account the bay position and type of structure, see Table 1,

$q \quad$ vertical applied load or sum of dead-load roof $+\Psi_{2}$ times vertical loads,

$l \quad$ span of one heated bay.

Table 1 Horizontal load acting on the cold structure during the collapse of the heated part.

\begin{tabular}{|c|c|c|c|c|c|}
\hline Fire location & $\mathrm{c}_{\mathrm{p}}$ & $\mathrm{n}_{\text {eff }}$ & $\mathrm{q}(\mathrm{N} / \mathrm{m})$ & $1(\mathrm{~m})$ & $\mathrm{F}(\mathrm{N})$ \\
\hline $1^{\text {st }}$ bay & 1.17 & 0.5 & 1726 & 18.9 & 19083 \\
\hline $2^{\text {nd }}$ bay & 1.17 & 1.0 & 1726 & 12.6 & 25445 \\
\hline $3^{\text {th }}$ bay & 1.17 & 1.0 & 1580 & 12.6 & 23292 \\
\hline $4^{\text {th }}$ bay & 1.17 & 0.5 & 1580 & 12.6 & 11646 \\
\hline
\end{tabular}

Through observation of the failure modes, it becomes clear that the columns with the non-structural concrete infills stay stable, which is why this method can be used. Maximum bending moment = $F^{*} 9.3 \mathrm{~m}=237 \mathrm{kNm} /$ frame.

\subsection{Bearing capacity of the foundations}

The horizontal force acting on the top of a structure will generate bending moments on the foundations. The base dimensions are $1.5 \times 1.5 \times 0.5 \mathrm{~m}^{3}$ starting at $-0.45 \mathrm{~m}$ (Figure 3 , left corner). In the halls, a concrete slab is foreseen from $0.15 \mathrm{~m}$, with top level at $0,00 \mathrm{~m}$, which can be assumed as fixed horizontally. The bending capacity of one foundation can be obtained as follows:

$$
H_{R d ; f i}=R_{d ; f i}+R_{p ; d ; i}=231 \mathrm{kN} / \mathrm{base}
$$

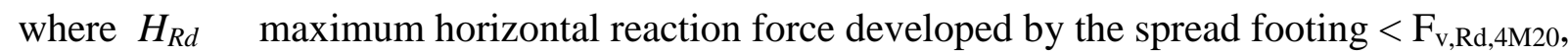

$R_{d ; f i} \quad$ friction part $=226 \tan \left(35^{\circ}\right)=158 \mathrm{kN}$,

$R_{p ; d ; i}$ passive earth pressure part $=73 \mathrm{kN}$ considering $\mathrm{K}_{\mathrm{p}}=3.7(\mathrm{EN} 1997-1)$.

$$
\begin{gathered}
x<H_{R d ; f i} /(180.30)=43 \mathrm{~mm} \\
M_{R d, f i}=(0.95-x / 2) \\
R_{d ; f i}+(0.45+0.50 / 2-x / 2) R_{p ; d ; f i}=196 \mathrm{kNm} / \mathrm{base}
\end{gathered}
$$

where $x \quad$ depth of part in compression on top of the slab with $\mathrm{C} 30 / 37$ concrete,

$M_{R d ; f i}$ resistance against overturning moment of one column base

This demonstrates that two foundations are sufficient to resist to the maximum bending moment. 


\section{SIMULATIONS}

Results of simulations are presented below. Failure of the heated part and fire resistance of the remaining sub-structure (including horizontal force) are listed for each configuration.

\subsection{Temperature on the non-heated side of a column partially subjected to fire}

Besides mechanical resistance, the EI criteria must also be fulfilled. In Figure 6, the timetemperature relationship is given on the symmetry axis of the HEB180 column, on the heated (node 94) and the opposite sides (node 117).

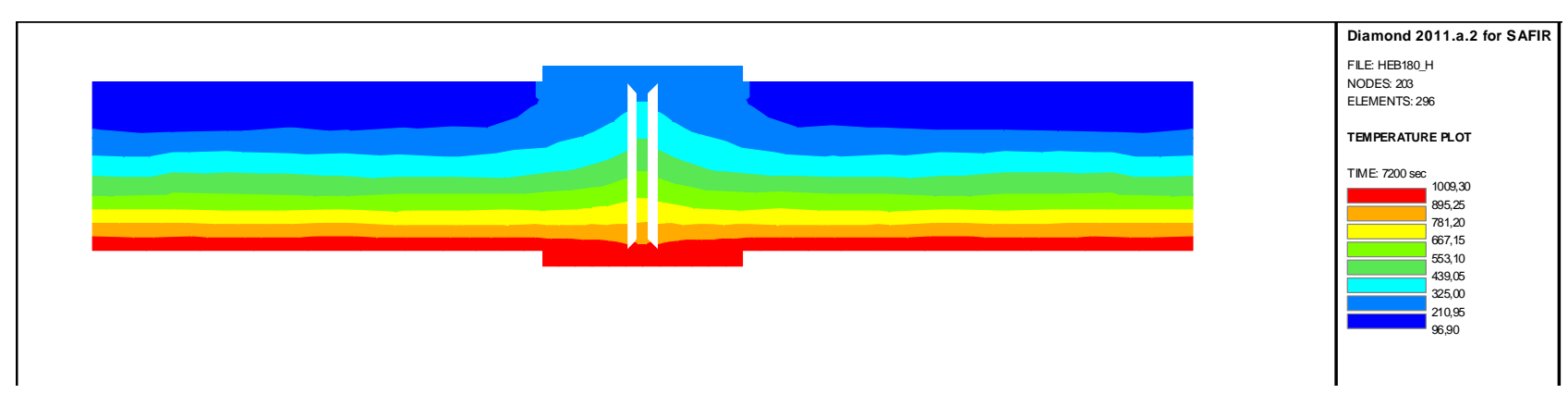

Figure 5. Temperature distribution after $120 \mathrm{~min}$

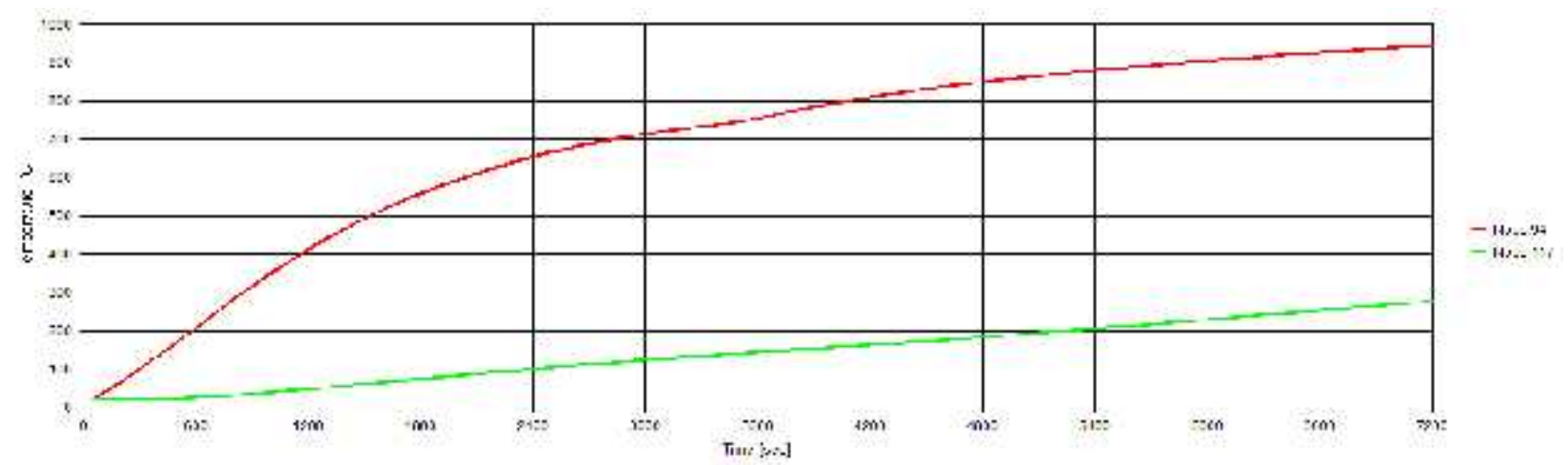

Figure 6. Evolution of the temperature till $120 \mathrm{~min}$ in the top and bottom HEB 180 flanges

After 87 minutes, the local temperature increase reaches $180^{\circ} \mathrm{C}$. Without further measures, the EI criterion is therefore limited to 87 minutes.

\subsection{Summary of mechanical results}

The results listed in Table 2 focus on the structural response to fire following the presented two-step thermo-plastic calculation.

Table 2. Failure time for fire in different bays.

\begin{tabular}{|c|c|c|c|c|c|}
\hline File name & Total \# bays & \# bays in fire & Position & Failure time & $2^{\text {nd }}$ step \\
\hline Sleurs_1 & 4 & 1 & 1 & $1237 \mathrm{~s}$ & $>7200 \mathrm{~s}$ \\
\hline Sleurs_2 & 4 & 1 & 2 & $3178 \mathrm{~s}$ & $>7200 \mathrm{~s}$ \\
\hline Sleurs_3 & 4 & 1 & 3 & $2719 \mathrm{~s}$ & $>7200 \mathrm{~s}$ \\
\hline Sleurs_4 & 4 & 1 & 4 & $1786 \mathrm{~s}$ & $>7200 \mathrm{~s}$ \\
\hline
\end{tabular}

Some extra simulations were done; without partition walls = failure at $1213 \mathrm{~s}$, same situation but with steel cladding instead of concrete in elevation $=1186 \mathrm{~s}$, with only 2 bays $=1209 \mathrm{~s} \&>7200 \mathrm{~s}$ and with only two bays and steel cladding $=1191 \mathrm{~s} \&>7200 \mathrm{~s}$. 
It seemed interesting to do the same simulation with LC panels $\left(\rho=650 \mathrm{~kg} / \mathrm{m}^{3}, \lambda=0.50 \mathrm{~W} / \mathrm{mK}, \mathrm{c}=\right.$ $840 \mathrm{~J} / \mathrm{kgK}, \alpha_{\mathrm{h}}=25 \mathrm{~W} / \mathrm{m}^{2} \mathrm{~K}, \alpha_{\mathrm{c}}=4 \mathrm{~W} / \mathrm{m}^{2} \mathrm{~K}$ and $\left.\varepsilon=0.70\right)$ and a void of even $20 \mathrm{~mm}$. To respect the same utilisation factor in ambient conditions the level of the roof edged was decreased by $3 \mathrm{~m}$. As a result the failure time of the heated sub-compartment was 1207 s for the Sleurs_1 scenario but still surpassed $7200 \mathrm{~s}$ for the residual structure. After 46 minutes the local temperature was higher than $200^{\circ} \mathrm{C}$, and the maximum after 7200 s was $437^{\circ} \mathrm{C}$ instead of $278^{\circ} \mathrm{C}$, as before.

\section{ANALYSIS OF A LOCALISED FIRE}

The ISO fire curve defined in EN 1991-1-2 is quite strict, but it was interesting to analyse the impact of a local fire situated just next to the column. Using FDS, two simulations were done, a surface of $1 \times 1 \mathrm{~m}^{2}$ at $0.5 \mathrm{~m}$ from the column and a second of $2 \times 2 \mathrm{~m}^{2}$ against the column (RHR $=500$ $\mathrm{kW} / \mathrm{m}^{2}$ ). The most severe thermal loading on the column was similar to the effect of the ISO 834 curve after about 7 minutes. For LC panels; $\lambda=0.50 \mathrm{~W} / \mathrm{mK}, \mathrm{c}=840 \mathrm{~J} / \mathrm{kgK}, \alpha_{\mathrm{h}}=25 \mathrm{~W} / \mathrm{m}^{2} \mathrm{~K}, \alpha_{\mathrm{c}}=4$ $\mathrm{W} / \mathrm{m}^{2} \mathrm{~K}$ and $\varepsilon=0.70$

\section{CONCLUSIONS}

As a result of numerous simulations, it can be concluded that, for multiple bay steel frame works with concrete infills (10 $\mathrm{mm}$ void) in the middle columns and rigid connection to the foundation, a fire resistance of up to $7200 \mathrm{~s}$ can be obtained without any protection of the steel structure. However, protection would be needed to fulfil insulation criteria higher than EI90. A R120 can also be reached with the use of LC-panels and a void of even $20 \mathrm{~mm}$, the proposed system seems to be robust. Protection will be needed in this case after 45 minutes to fulfil EI criteria.

The failure modes are consistent with the observations made for a similar partition wall after a real fire. If they pass the roof, they may be marked as real fire walls between compartments. Connections between beams and columns must be designed as rigid at ambient temperature.

\section{ACKNOWLEDGMENTS}

The publication could not have been achieved without the educational efforts of ArcelorMittal in the Secure With Steel network, the enthusiasm of the staff, interesting questions from Metaalwerken Ivo Gijbels, and information from Euroshoe. We would like therefore like to thank all of them for their support.

\section{REFERENCES}

Belgian Welding Institute, 2008: Replica investigation and surface hardness measurements on four vertical HEA180 profiles after exposure to fire, Gent (in Dutch).

Eurocode 1, EN 1991-1-2:2002; Actions on structures - Part 1-2: General actions - Actions on structures exposed to fire, European Committee for Standardization CEN, Brussels, 2002.

Eurocode 1, EN 1991-1-4:2005; Actions on structures - Part 1-4: General actions - Wind actions, European Committee for Standardization CEN, Brussels, 2005.

Eurocode 3, EN 1993-1-2:2005; Design of steel structures - Part 1-2: General rules - Structural fire design, European Committee for Standardization CEN, Brussels, 2005.

Eurocode 4, EN 1994-1-2:2005; Design of composite steel and concrete structures - Part 1-2: General rules Structural fire design, European Committee for Standardization CEN, Brussels, 2005.

Eurocode 7, EN 1997-1:2004; Geotechnical design - Part 1: General rules, European Committee for Standardization CEN, Brussels, 2004.

Franssen J.-M., SAFIR. a thermal/structural program modelling structures under fire, Engineering Journal, A.I.S.C., 2005; Vol 42, No. 3, 143-158.

RFSC Research: Fire safety of industrial hall, Design Guide, Arcelor Mittal, CTICM, Labein tecnalia, ULg, Director-General for research, Research Fund for Coal and Steel Unit, RFSC2-CR-2007-00032, Luxembourg, 2007.

RFSC Research: Fire safety of industrial hall, Background Document, Arcelor Mittal, CTICM, Labein tecnalia, ULg, Director-General for research, Research Fund for Coal and Steel Unit, RFSC2-CR-200700032, Luxembourg, 2007. 